\title{
Efficiency Performances of Two MPPT Algorithms for PV System With Different Solar Panels Irradiances
}

\author{
Ali Abdulwahhab Abdulrazzaq, Adnan Hussein Ali \\ Middle Technical University, Technical Instructors Training Institute, Baghdad, Iraq
}

\begin{abstract}
Article Info
Article history:

Received Jun 29, 2018

Revised Sep 12, 2018

Accepted Sep 26, 2018

\section{Keyword:}

Solar photovoltaic (PV)

Perturb and Observe (P\&O)

Incremental Conductance (INC)

algorithms

MPPT techniques

Constant \& variable Irradiation

ABSTRACT

A main source of current renewable energy is solar energy. This source of renewable energy can be converted to electrical energy using solar photovoltaic (PV) cells. The Maximum Power Point Tracking (MPPT) earns for maximum energy extractor from PV panels by different irradiance levels. In this paper, overall efficiency of most two popular MPPT techniques utilized in PV applications are analyzed, these algorithms are Perturb and Observe (P\&O) and Incremental Conductance (INC). An analysis of the results for the algorithms based on MATLAB simulation for various changes in solar irradiance is performed. Results showed that the efficiency of P\&O algorithm was higher than that of the INC, but to obtain the same performance for both, more concentrated calculations should be used for INC. In measuring the output power, current and voltage responses, the use of a solar array having constant and variable irradiations was employed as input for the algorithms. The output waveforms which were derived from a simulation run for the purpose of obtaining the algorithms response to changes in solar array irradiations were compared. In general, the consequences of the $\mathrm{P} \& \mathrm{O}$ algorithm are quiet good and adequate. However, there is a need to improve the algorithm so as to satisfy the requirements of face confident timing in addition to its rapid response so as to make its performance better than that of InCond algorithms.
\end{abstract}

Copyright (C) 2018 Institute of Advanced Engineering and Science. All rights reserved.

\section{Corresponding Author:}

Dr Adnan Hussein Ali

Middle Technical University,

Technical Instructors Training Institute, Baghdad, Iraq

Email: aaddnnaann63@yahoo.com

\section{INTRODUCTION}

In recent times, the mechanisms for converting solar energy has made it to be available in significantly compact size. The development of such an effective system which is small yet powerful enough to meet high electric power demand, has been made possible for engineers in the field of power electronics through research advancement. Energy can be generated from solar which is widely accessible on the earth's surface; this solar can be converted into the kind of energy humans require and it can be used efficiently [1]. Generating power from solar, a standalone or grid-connected power generating system can be used, depending on factors like load area location, utility and availability of a close-by power grid [2].

Although PV systems have enjoyed great advances like improved cell efficiency and cost reduction, the widespread use of the PV systems have been significantly restricted by low energy conversion efficiency. More so, environmental factors like solar radiance besides surrounding temperature significantly determine the energy amount which can be produced. Thus, a suitable MPPT is required by the control unit to be able for obtaining the maximum power generated from the output PV array, which can be then turn enable a provision of a duty cycle that is appropriate for the DC-DC converter $[3,4]$.

A solar cell has low efficiency and its efficiency can still not be improved by connecting the solar cells for the formation of a panel [5]. Therefore, one way through which the efficiency $(\eta)$ of solar cell can 
be improved is through the application of theorems of the maximum power transfer, that states the power transfer occurs when there is a correspondence between the source output resistance and resistance of the load, which means impedance of a solar cell or panel. Thus, the MPPT techniques principle relies on the theorem of maximum power transfer, which always seeks to match the impedance of load to source [6].

Owing to the I-V non-linearity characteristics in the power generation of PV systems, the MPPT now comes in both grid-connected and standalone power generation systems. This makes supplying steady power to a specific load difficult. Including the MPPT technology to the PV system designing considers a good way to enable the transfer of most stable and highest possible power from source to load. The reason behind this is the continuous variation in the power which these panels generate, depending on weather related factors like temperature and irradiance; the efficiency with which power is converted looks very low, with just not more than $15 \%$ of the total converting energy from sunlight becoming electricity [7].

Thus, the inclusion of MPPT in PV systems to confirm that a solar panels generate the maximum power amount. A nonlinear correlation is demonstrated by the characteristics of PV panel (I-V \& P-V) between irradiances \& temperature. Nonetheless, a special point where the whole system can function with high efficiency can be found in the characteristic curve is presented in Figure 1. This unique fact is denoted to maximum power point MPP, which can be considered to ensure that the PV system is functioning at it in the production of the maximum amount of power, calculations, monitoring and control techniques are required [8].

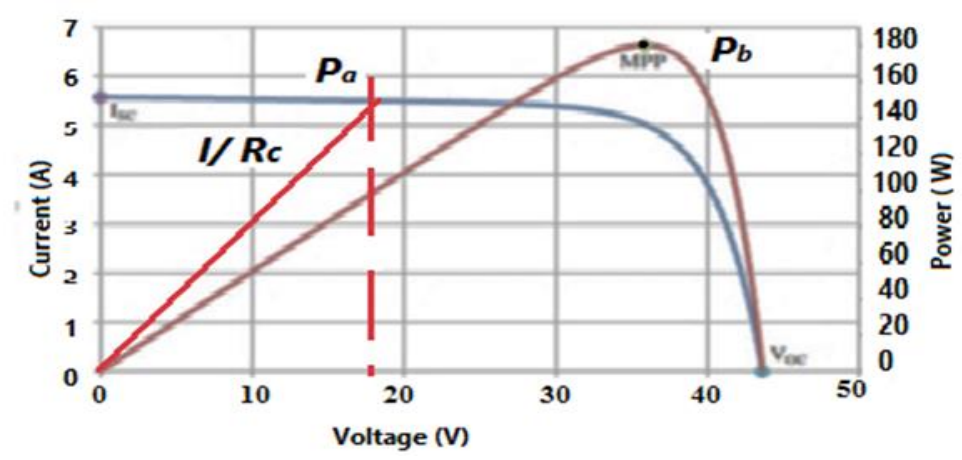

Figure 1. Characteristic I-V and P-V curves of a solar panel

The output of power varies just as there is a variation in the solar radiation. Figure 1 explains the maximum power tracking principles, where the sloppy line I/Rc connotes a constant load Rc. The direct connection of this load across PV cell will result in it operating a power $\mathrm{Pa}$ which is not the same as the maximum $\mathrm{P}_{\mathrm{b}}$, despite the availability of the maximum power from the array. So, an introduction to the DCDC converter or a power conditioner is concerning the solar PV module in addition to the load. The load is adapted to the PV array through the use of this converter in order to enable the transformation of the characteristics along the locus of maximum points, thereby leading to the transformation of maximum power from the array. This change is made to the duty cycle of " $\mathrm{D}$ " till the time when the peak power point is achieved [9-10].

The MPPT can be regarded as an electronic device which can be used to extract the maximum potential power from a solar panel. The MPPT changes the duty cycle of the DC/DC converter to match the impedance of the load with a PV cell, thereby leading to a variation in the panel's electrical operating point. Despite the fact that the Mechanical tracking system and MPPT can use together, it is important to note that they are totally two different systems.

Over the past decades, many MPPT techniques have been analyzed. The first objective of this paper is to study and analyze them. The most two algorithms that were found most suitable for medium and large size PV applications are perturb and observe $(\mathrm{P} \& \mathrm{O})$, and incremental conductance (INC). These were compared and tested dynamically according a recently issued standard concerned irradiation and temperature. Several modifications to the $\mathrm{P} \& \mathrm{O}$ and the INC algorithms are proposed, which overcome their poor performance when the irradiation changes continuously using MATLAB simulation which are mostly mentioned in the literatures were made, and they present advantages for constant and variable irradiations in related to other techniques with efficiency, output power of MPP. 


\section{MPPT ALGORITHMS}

Recently, the introduction of optimization algorithms for MPPT in PV systems have been made. The MPP can be randomly searched across the P-curve area through the use of the stochastic characteristic of optimization algorithms, thereby making it fit for tracking the GMPP. Owing to the variation in the MPP of a solar panel caused by temperature and irradiation, MPPT algorithms become crucial in PV applications. This is because MPPT algorithms enhance the generation of maximum power from a solar array [11].

Various methods of finding the MPP have been developed and published in the past decades. All these techniques are not similar because of the variation in their cost, sensors, convergence speed, complexity, accurate tracking during changes in temperature and/or irradiation. The most commonly used techniques out of all that have been developed are Perturb and observe (P\&O) and Incremental conductance (INC) which are more advantageous because of their ease of implementation. However, they also have their limitations. The other techniques which have been developed according to different principles include neural network, current sweep technique, fuzzy logic control, and fractional open circuit open voltage or short circuit current, and this technique is able to provide an estimated MPP.

Both algorithms P\&O and INC are established on the principles of hill-climbing basis, which involves the movement of the operation point of the PV array in the direction that directs for increasing power. The easy implementation of hill-climbing techniques as well as its efficiency when irradiation is constant, makes it one of the most common MPPT methods [12]. Both are advantageous because of the low computational power which they require as well their simplicity.

The optimization algorithm $\mathrm{P} \& \mathrm{O}$ is made up of converter input current or voltage reference which vary. A measurement of the power's amount which is panel conversation has been taken. If the converted amount of power is more than that which was previously measured, it implies a proportional steady increase in the voltage reference, but if not, it implies a decrease. Finding the optimum MPPT requires continuously taking the steps. In some situations, the MPP may not be able to find, particularly under partial shading, is regarded as the limitation of this algorithm.

The implementation of the algorithm as well as taking it as a reference point is a good idea because it is an algorithm which is commonly used. It's flow chart can be seen in figure 2, where $\mathrm{Y}(\mathrm{t})$ represents the reference signal that might be either voltage or current solar PV. For achieving MPP is the main purposing, the system operating point could be changed with a small perturbation $(\Delta \mathrm{Y})$ is applied to the reference signal of the solar PV and then measuring the output power after each perturbation. A comparison is made, if the measured power is more value with respect to the preceding value, after that a reference signal perturbation will continue in the same direction. Generally, when a measuring power of the solar PV stands a smaller amount with respect to the former value, a perturbation will be utilized with reverse direction and then a procedure will continue to achieve the MPP.

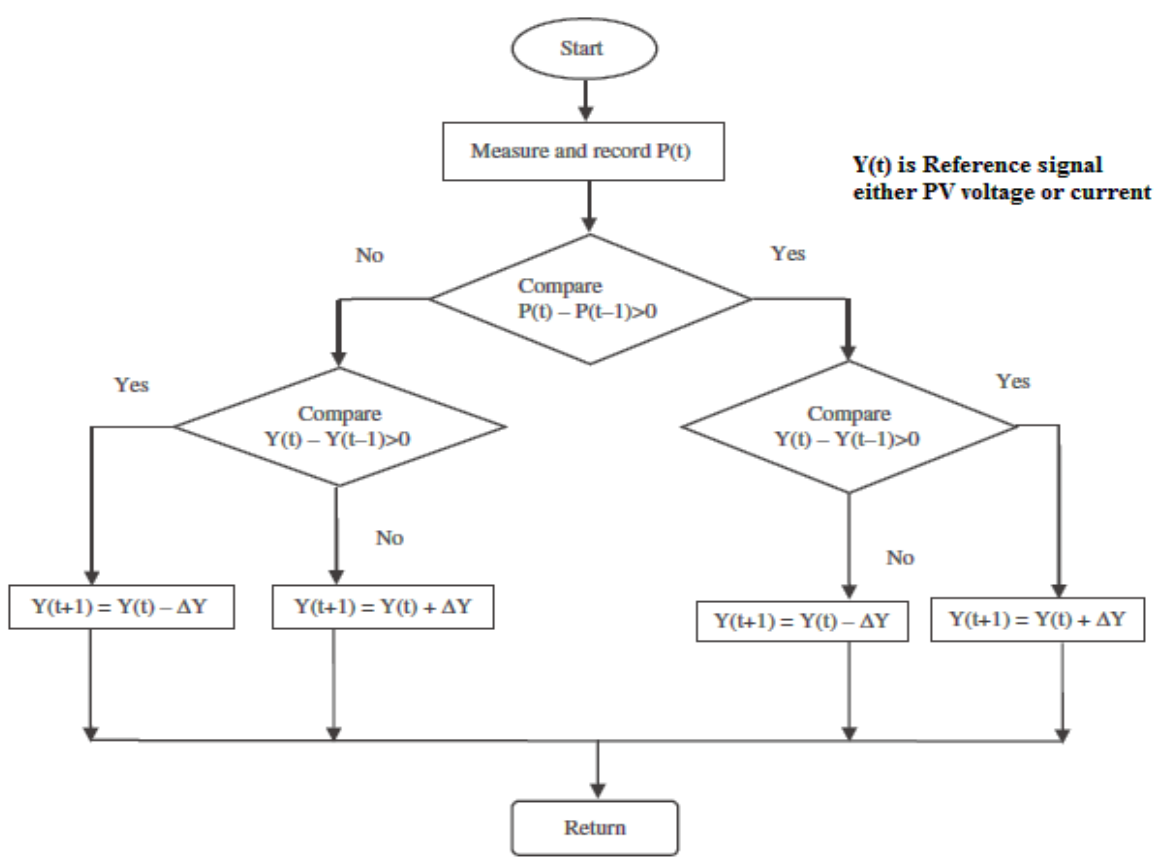

Figure 2. Flowchart of conventional MPPT P\&O algorithm 


\subsection{Incremental Conductance}

The INC algorithm is constructed on the fact concerning a slope of the power curve against each of voltage or current of the PV module considers zero at the MPP, a movement of positive or negative towards the left of it and on the right is negative or positive, as explain in Figure 3.

- $\Delta V / \Delta P=0(\Delta I / \Delta P=0)$ at the MPP

- $\Delta V / \Delta P>0(\Delta I / \Delta P<0)$ on the left

- $\Delta V / \Delta P<0(\Delta I / \Delta P>0)$ on the right

When a comparison of the power increment against the voltage or current increment through two successive samples is made, then a MPP voltage change may be specified. The tracking of the MPP can done by a comparison of the instantaneous conductance term $(I / V)$ with an incremental value $(\Delta I / \Delta V)$ as illustrated in the flowchart, figure. 4 . A reference voltage $V_{\text {ref }}$ represents a PV array point which is required to control. The $V_{\text {ref }}$ at MPP equals $V_{m p p}$, once an MPP is reached, then the operation of the PV array is_maintained at this point if no change in $\Delta \mathrm{I}$ has happened, or specifying a variety of atmospheric condition $[13,14]$.

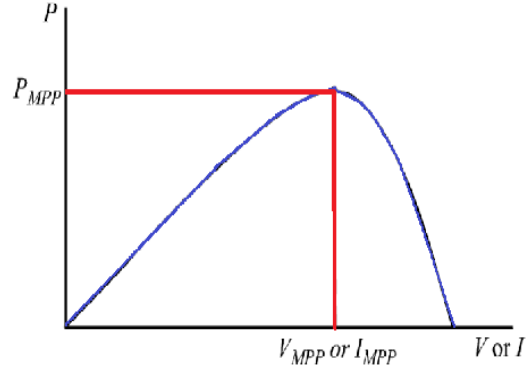

Figure 3. PV array Characteristic power curve.

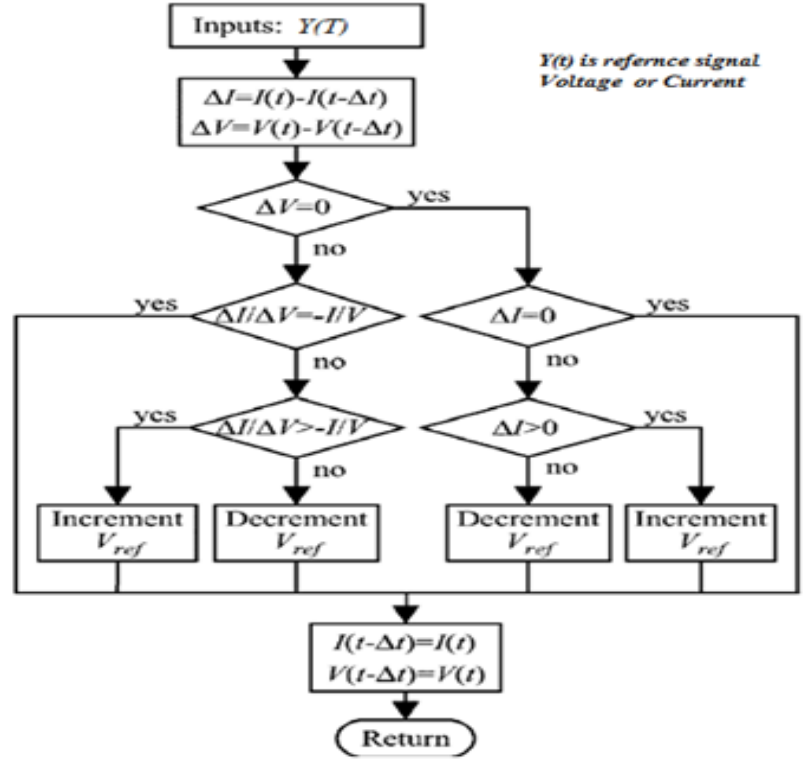

Figure 4. INC algorithm flowchart

\subsection{Solar Array} enveloped:

For a component of solar array, based on the diode equation below, a model of the array is

$$
\mathrm{Id}=\mathrm{Isat}(\mathrm{eqVd} / \mathrm{kT}-1)
$$

where Id indicates the diode current (A), Vd represents the diode voltage $(\mathrm{V})$. In order to perform the simulation, a selection of a solar array that is capable of producing more than $100 \mathrm{~W}$ was made. The first condition is concerned with voltage Voc (open circuit) of $22 \mathrm{~V}$ and current Isc (short circuit) of 8.4A will be possessed by the panel. The Vmp- voltage at maximum power- is $17.5 \mathrm{~V}$ whereas the current Imp - maximum power- is 7.7A. Concerning a full solar illumination, an output power of $135 \mathrm{~W}$ can be obtained from the solar array by plugging these values into $\mathrm{P}=\mathrm{IV}$.

Figure 5 shows that varying the PV solar array incident illumination alongside the output impedance, implies that the extraction of Power versus Voltage and Current versus Voltage graphs can be performed so as to achieve the MPP of the solar array. The MPP is the power peak versus Voltage graph. If the incident illumination of the PV solar array is varying in addition to the output resistance, A graphs of Power against Voltage as well as Current against Voltage can be extracted for finding the solar array MPP, as shown in figure 5. 

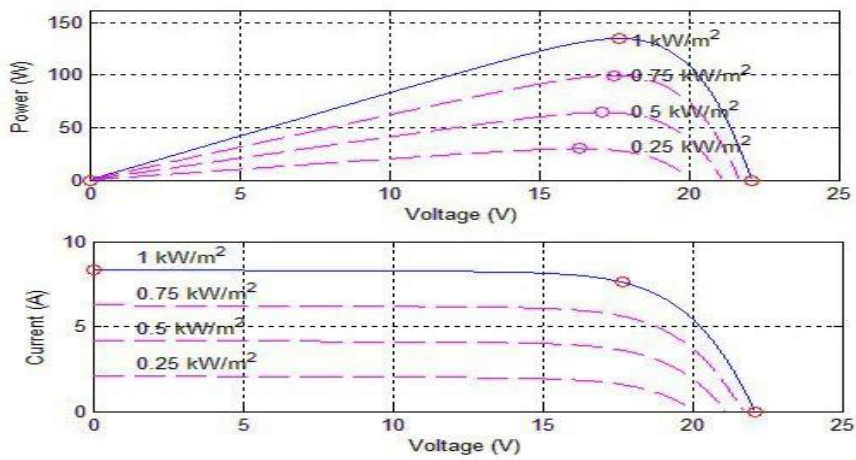

Figure 5. Power vs Voltage \& Current vs Voltage graphs from PV panel model

\section{CHARATERISTICS OF PV SYSTEM}

In order to provide a description of the features of (I-V) characteristic of the solar cells in various operating conditions, many models have been designed in the literature. The solar cell behavior is commonly represented by a single-diode model besides double-diode model [15].

The PV panel consists of a PV set cell which is arranged in a serial and parallel order so as to generate a normal maximum electrical power which is dependent on the conversion efficiency of semiconductor photo-energy organizing the cells. A PV cell may be regarded like generator that produces a photo-current Iph that depends on external factors like panel direction or working temperature. Presently, the one-diode model represents the PV cells (Fig. 6-a) and the double-diode model (Fig. 6-b) represents the different parameters of the model [16].

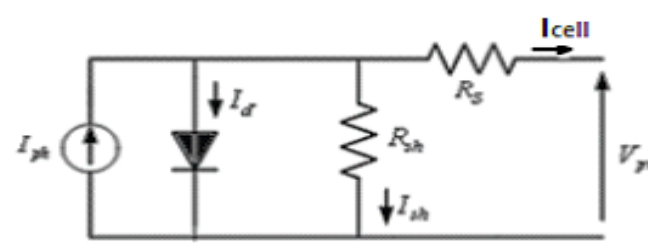

Figure 6 (a) PV cell Equivalent circuit

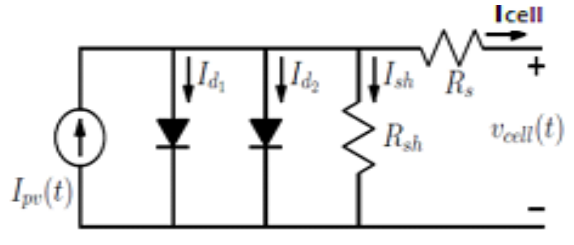

(b) PV panels double-diode model

The currents equation describing one diode model is

$$
I_{\text {cell }}=I_{p v}=I_{p h}-I_{D}-I_{S H}
$$

The current supplied by the cell $I_{p h}$ is

$$
I_{p h}=I_{p v}+I_{s a t}\left[\exp \left(\frac{p\left(V_{p v}+\left(I_{p v^{*} R_{S}}\right.\right.}{n K T}\right)-1\right]+\frac{V_{p v}+\left(I_{p v^{*} R_{S}}\right)}{R_{S h}}
$$

The model of the PV panel centered on double diodes can be presented in figure 6-b. Subsequently, output the current $I_{\text {cell }}$ can be denoted by

$$
I_{\text {cell }}=I_{p h}-I_{d 1}-I_{d 2}-I_{s h}
$$

where $I_{p h}$ represents current that has been generated from the light incident on the panel. More so, the diodes currents, by diffusion $I_{d 1}$ plus recombination mechanism $I_{d 2}$, and the shunt current by $R_{s h}$ which denotes to the panel loss, and be related to the Vcell can be given in Eq. (5).

$$
\begin{aligned}
& I_{d l}=I_{s i}\left[\exp \left(\frac{\left(V_{\text {cell }}+\left(I_{\text {cell }} * R_{S}\right.\right.}{n i * V t}\right)-1\right] \text { for } i=1,2 \\
& I s h=\left(\frac{\left(V_{\text {cell }}+\left(I_{\text {cell }} * R_{S}\right.\right.}{R s h}\right)
\end{aligned}
$$

where Isi is the diodes reverse saturation current, and $V t=k / T q$ is the panel thermal voltage. 


\subsection{MPPT Operating Zone for DC-DC Converter Topology}

The solar PV's MPPT operating zone relies on the topology of DC- DC converter, and the resistive load value is restricted thereby making the MPPT effective. The implementation of the MPPT is carried out under the converter control, i.e. it causes variation in the duty cycle (d). The main aim of making adjustments to the duty cycle is for matching the load impedance to the input impedance Rin which is noticed by the converter. Figure 7 shows the solar PV impedance. There is a relationship between the Rin noticed by the converter and the Ro connected with converter by characteristic equations. There is variation in this mathematical equation, depending on the topologies of converter [17].

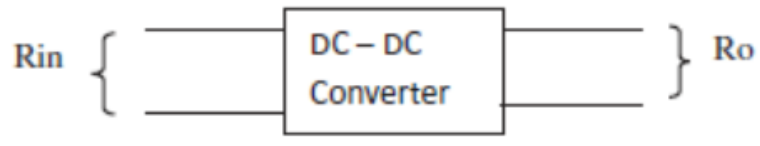

Figure 7. DC-DC converter diagram

The implementation of the improved MPPT structure is performed using the DC-DC buck converter as shown in Figure 8. The output voltage of solar PV is derived from the buck converter input voltage. The relationship between the (input and output voltage) buck converter is given by equation 6 .

$$
\nu_{0}=d \cdot \nu_{\text {in }} \quad \text { (6) }
$$

Where the output voltage is denoted by Vo, the duty cycle is d and input voltage Vin of the buck converter.

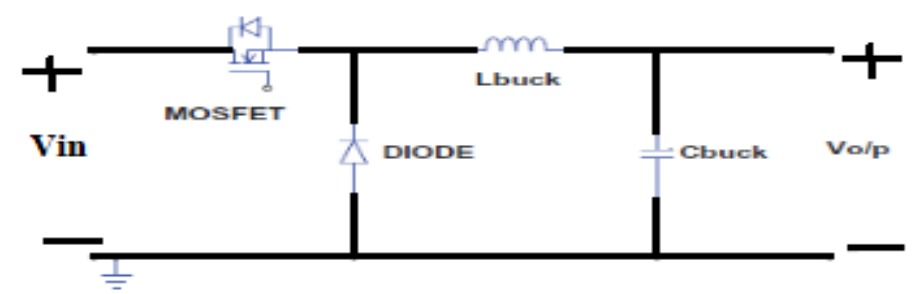

Figure 8: Buck converter diagram

\section{COMPARISON OF CONTROL ALGORITHM}

Understanding the way these algorithms respond to various changes of solar array irradiance is possible through a comparison of the output waveforms from each run.

\subsection{Case 1: P\&O at Constant Irradiance}

A first MATLAB model run is done with a constant input irradiance by the solar array. A measurable amount of ripple is possessed by the response curve, which represent the output voltage as presented in Figure 9.a. When there is little initial overshoot at the current response, the PWM of the gate is controlled by the MPPT so as to bring it near the MPP as explained in Figure 9.b. In Figure 9.c the output power stays almost constant from $3 \mathrm{msec}$ and above. A constant efficiency of $94 \%$ is achieved by the converter and then throughout the period of simulation the steady efficiency remains almost completely flat as presented in Figure 9.d. 


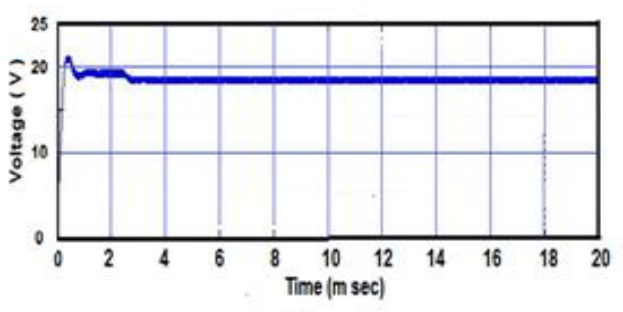

(a)

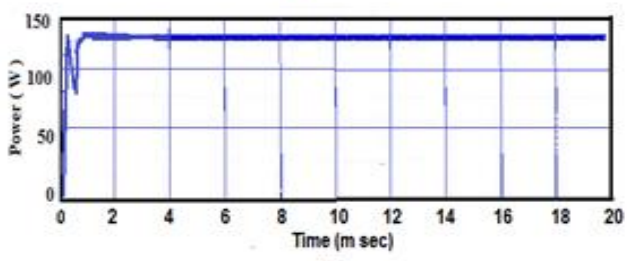

(c)

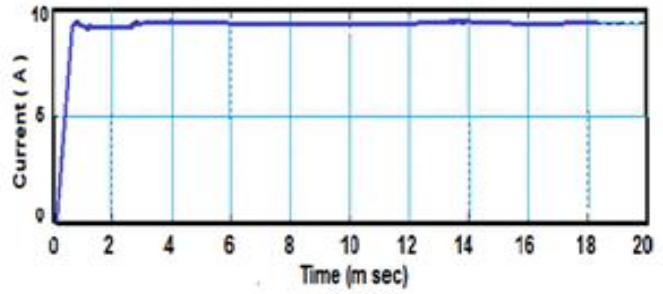

(b)

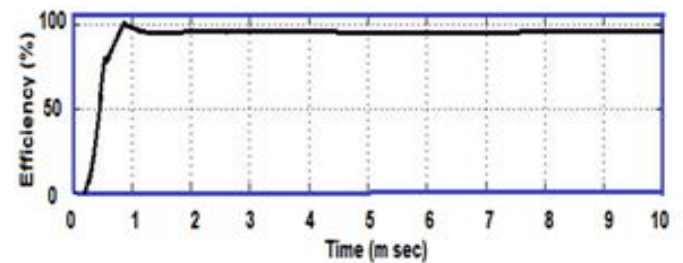

(d)

Figure 9: $\mathrm{P} \& \mathrm{O}$ simulation result at constant irradiance (a) output voltage (b) current response (c) output power (d) efficiency

\subsection{Case 2: P\&O with Variable Irradiance.}

A second case involves simulation using variable irradiance to the input solar array. The changes in irradiance are tracked by both the source and output voltage as presented in figure 10.b. Little start-up overshoot occurs in the current response to every change in irradiance. During the operation, there was a tendency of the source current oscillating a bit as shown in Figure 10.c. In comparison to the input power which is shown in Figure 10.d, the output power remains relatively close in magnitude. Due to the fact that the average of over 0:0001 was achieved by the input and output power, efficiency of the converter shot to over $100 \%$; this caused a little slow down in the input power. In general, it can be said that despite the sudden changes in irradiance, the efficiency did not go below $80 \%$ as illustrated in Figure 10.e.
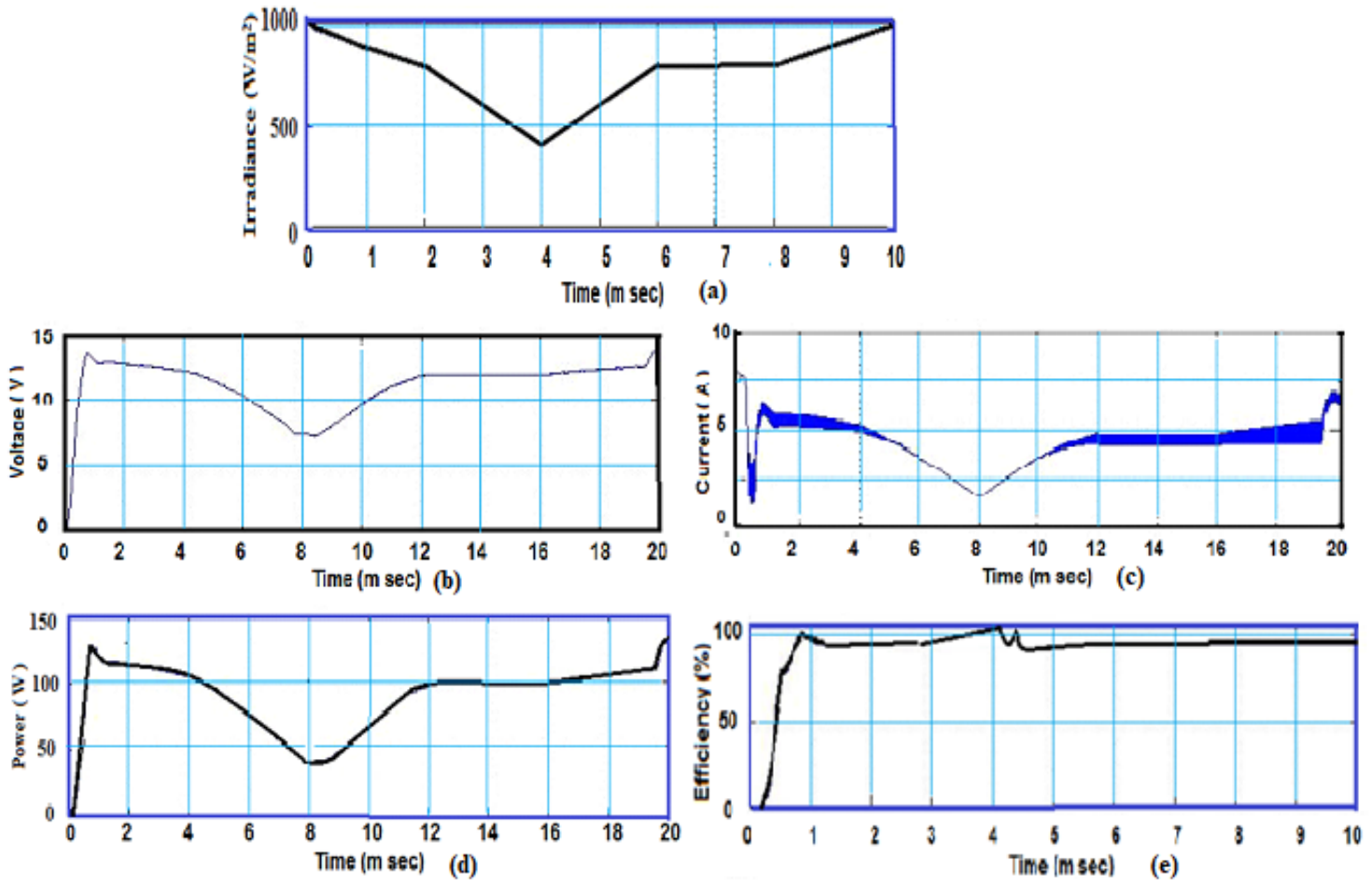

Figure 10. $\mathrm{P} \& \mathrm{O}$ simulation result at variable irradiance (a) irradiance (b) output voltage (c) current response (d) output power (e) efficiency 


\subsection{Case 3: INC with Constant Irradiance}

The simulation of INC algorithm at constant input radiance is used by this run. It took a longer period of time for the source voltage to reach a level that is acceptable. The tracking of the MPP by the algorithm begins, but does not eventually reach the MPP because of the short duration of the run. Even though, Figure 7.a shows that the tracking is moving in the right direction even it eventually reaches the MPP within the next few algorithm repetitions, it ended up not doing so. Figure 7.b shows that while MPP is being tracked, the inductor current possesses four jumps in D. It only takes this algorithm few iterations before it converges to the MPP when the final output power is close to $120 \mathrm{~W}$ as illustrated in Figure 7.c. Figure 7.d shows that the efficiency for almost throughout the duration of the run was $97 \%$.

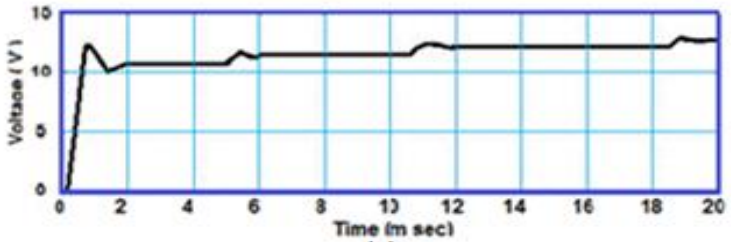

(a)

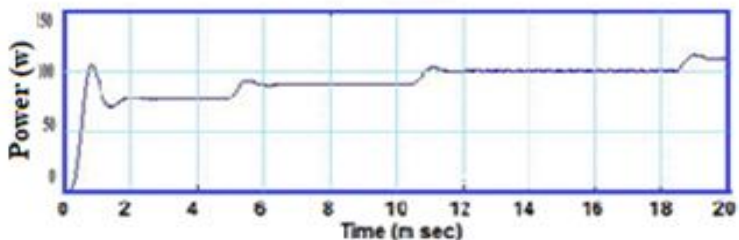

(c)

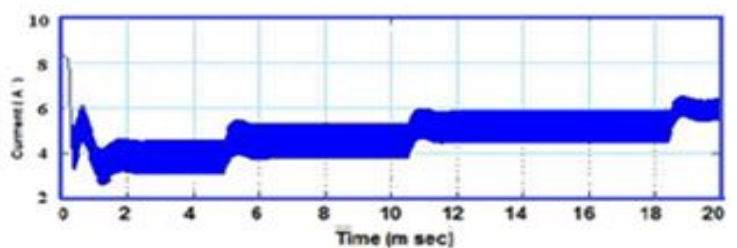

(b)

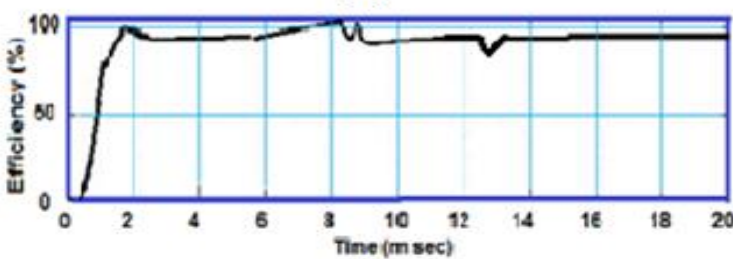

(d)

Figure 11: INC algorithm simulation result at constant irradiance (a) output voltage (b) current response (c) output power (d) efficiency

\subsection{Case 4: INC with Variable Irradiance.}

The final simulation of INC algorithm deals with variable irradiance applied to the solar array. Figure 12.a illustrates that the response of the source and output voltage is restricted subsequent for changing in the irradiance. The current response is shown in figure 12.b, a change as stair step occurs in the figure after $8 \mathrm{msec}$. The tracking of the MPP by the power output was quite successful as seen in Figure 12.c. The occurrence of the largest oscillation was when the efficiency was calculated. For the capacitor and inductor to get back to a lower level of output power, more time is required. More so, this also caused an increase in the efficiency of the converter subsequent to the increase in irradiance as shown in Figure 12.d.

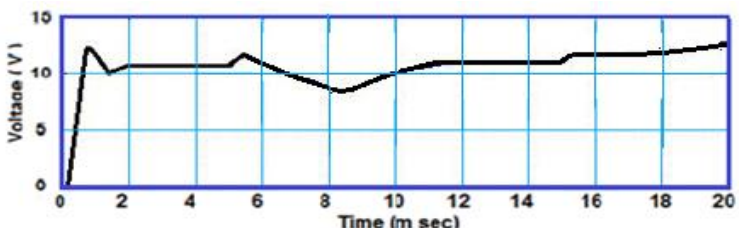

(a)

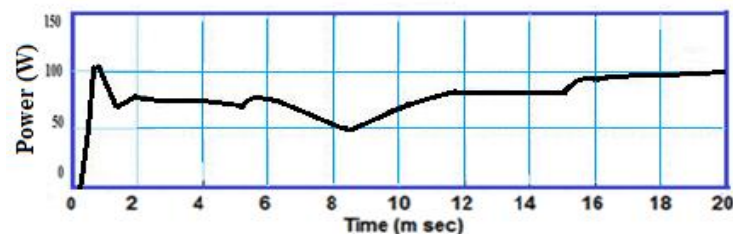

(c)

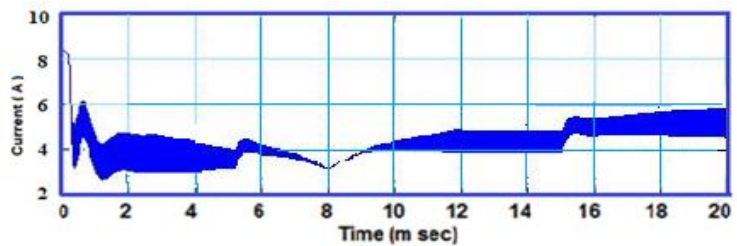

(b)

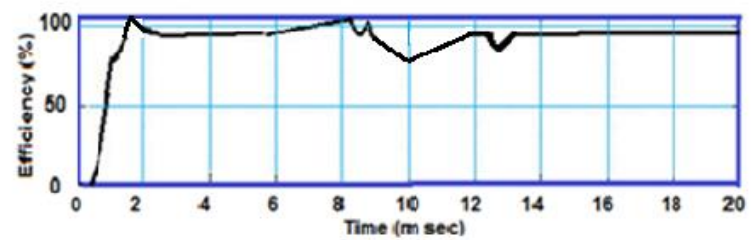

(d)

Figure 12: INC algorithm simulation result at variable irradiance (a) output voltage (b) current response (c) output power (d) efficiency 


\section{CONCLUSION}

A discussion of the MPPT was done in this article, and its tracking was also significantly improved. The MPPT's ability to track the MPP, enhanced its ability to optimize the low efficiency of the output of solar arrays. The overall system can greatly be improved when the MPPT capable of tracking the MPP is improved because the solar array is the systems' power source.

Furthermore, a discussion on the solar array model was done, and the single diode model was used in designing the solar array. A measurement of the output current and voltage was made possible through the modeling of the solar array using the measuring parameters, output current and voltage which were used in driving the buck converter.

An existing assembly of data runs was carried out in two phases. The first phase involved using the $\mathrm{P} \& \mathrm{O}$ algorithm at constant $1000 \mathrm{~W} / \mathrm{m}^{2}$ irradiance, a variable step in irradiance from $600 \mathrm{~W} / \mathrm{m}^{2}$ to $1000 \mathrm{~W} / \mathrm{m}^{2}$ at $0: 08 \mathrm{~s}$ to $0.01 \mathrm{~s}$, in addition to random varying of irradiance in the solar array.

Afterwards, the same three input signals were used in testing constant $\mathrm{D}$. The testing of $\mathrm{D}$ was done as the basis for comparing it with other algorithms. Lastly, the testing of the INC was performed, even though tuning the parameters for this algorithm was not easy. It was observed that very rapid response to transients or undershooting of the MPP was caused by the algorithm. The optimization of the INC algorithm to correspond with the $\mathrm{P} \& \mathrm{O}$ performance was not possible due to the time required to perform every test as well as the difficulty of optimization.

In general, the test results of the $\mathrm{P} \& \mathrm{O}$ algorithm were relatively good. The response of the $\mathrm{P} \& \mathrm{O}$ algorithm was faster and its performance was better than that of INC, because of the algorithm's ability to be optimized to meet specific timing requirements. This can be attributed to the complex nature of the computations for INC algorithm as well as operation speed. The optimal functioning of the algorithm could not be accurately provided by the results of the runs as a result of how difficult it is to optimize the INC algorithm.

\section{REFERENCES}

[1] Ahmed J, Salam Z. An improved perturb and observe (P\&O) maximum power point tracking (MPPT) algorithm for higher efficiency. Appl Energy 2015;150:97-108.

[2] Zhao, J.; Zhou, X.; Ma, Y.; Liu,W. A novel maximum power point tracking strategy based on optimal voltage control for photovoltaic systems under variable environmental conditions. Sol. Energy 2015, 122, 640-649.

[3] Kuperman, A.; Averbukh, M.; Lineykin, S. Maximum power point matching versus maximum power point tracking for solar generators. Renew. Sustain. Energy Rev. 2013, 19, 11-17.

[4] Seyedmahmoudian, M.; Mekhilef, S.; Rahmani, R.; Yusof, R.; Asghar Shojaei, A. Maximum power point tracking of partial shaded photovoltaic array using an evolutionary algorithm: A particle swarm optimization technique. J. Renew. Sustain. Energy 2014, 6.

[5] Sheik, S.; Devaraj, D.; Imthias, T. A novel hybrid Maximum Power Point Tracking Technique using Perturb \& Observe algorithm and Learning Automata for solar PV system. Energy 2016, 112, 1096-1106.

[6] M. Abdur Razzak, et al.,, Design of a Grid-connected Photovoltaic Inverter with Maximum Power Point Tracking using Perturb and Observe Technique, International Journal of Power Electronics and Drive System (IJPEDS) Vol. 7, No. 4, December 2016, pp. 1212 1220.

[7] J. Ahmed and Z. Salam, "A Modified P\&O Maximum Power Point Tracking Method With Reduced Steady-State Oscillation and Improved Tracking Efficiency," IEEE Transactions on Sustainable Energy, vol. 7, no. 4, pp. 1506$1515,2016$.

[8] Huynh, D.C.; Dunnigan, M.W. Development and Comparison of an Improved Incremental Conductance Algorithm for Tracking the MPP of a Solar PV Panel. IEEE Trans. Sustain. Energy 2016, 7, 1421-1429.

[9] Karami, N.; Moubayed, N.; Outbib, R. General review and classification of different MPPT Techniques. Renew. Sustain. Energy Rev. 2017, 68, 1-18.

[10] Seyedmahmoudian, M.; Horan, B.; Soon, T.K.; Rahmani, R.; Oo, A.M.T.; Mekhilef, S.; Stojcevski, A. State of the art artificial intelligence-based MPPT techniques for mitigating partial shading effects on PV systems-A review. Renew. Sustain. Energy Rev. 2016, 64, 435-455.

[11] M. A. Abdourraziq and M. Maaroufi, "Experimental Verification of the Main MPPT Techniques for Photovoltaic System", International Journal of Power Electronics and Drive Systems (IJPEDS) Vol. 8, No. 1, March 2017, pp. $384-391$

[12] Soon, T.K.; Mekhilef, S. A fast-converging MPPT technique for photovoltaic system under fast-varying solar irradiation and load resistance. IEEE Trans. Ind. Inform. 2015, 11, 176-186.

[13] Jedari, M.; Gharehpetian, G.; Fathi, S.H.; Vahids, S. An adaptive InCon MPPT algorithm considering irradiance slope tracking for PV application. In Proceedings of the 2016 4th International Symposium on Environment Friendly Energies and Applications (EFEA), Belgrade, Serbia, 14-16 September 2016; pp. 1-6.

[14] K. S. Tey and S. Mekhilef, "Modified incremental conductance algorithm for photovoltaic system under partial shading conditions and load variation," IEEE Transactions on Industrial Electronics, vol. 61, no. 10, pp. 5384-5392, 2014 . 
[15] H. Islam , S. Mekhilef, N. Mohamed Shah, T. K. Soon , M. Seyedmahmousian, B. Horan, and A. Stojcevski. Performance Evaluation of Maximum Power Point Tracking Approaches and Photovoltaic Systems, Energies 2018, $11,365$.

[16] Ahmed J. Abid, Fawzi M. Al-Naima and Adnan Hussein Ali, " Comprehensive Modeling of Photovoltaic Array based on Proteus Software", International Journal of Applied Engineering Research , Volume 13, Number 6 (2018) pp. 4440-4447.

[17] J. Ahmed, and Zainal Salam, An Enhanced Adaptive P\&O MPPT for Fast and Efficient Tracking Under Varying Environmental Conditions, accepted for publication in a future issue of IEEE Transactions on Sustainable Energy, DOI 10.1109/TSTE.2018. 